University of Nebraska - Lincoln

DigitalCommons@University of Nebraska - Lincoln

Faculty Publications: Department of

Entomology

Entomology, Department of

1999

Distribution and Inhibition of Esterases in Various Body Tissues of

Susceptible and Resistant German Cockroaches (Dictyoptera:

Blattellidae)

No-Joong Park

University of Nebraska-Lincoln

Shripat T. Kamble

Universitiy of Nebraska--Lincoln, skamble1@unl.edu

Follow this and additional works at: https://digitalcommons.unl.edu/entomologyfacpub

Part of the Entomology Commons

Park, No-Joong and Kamble, Shripat T., "Distribution and Inhibition of Esterases in Various Body Tissues of Susceptible and Resistant German Cockroaches (Dictyoptera: Blattellidae)" (1999). Faculty Publications: Department of Entomology. 303.

https://digitalcommons.unl.edu/entomologyfacpub/303

This Article is brought to you for free and open access by the Entomology, Department of at DigitalCommons@University of Nebraska - Lincoln. It has been accepted for inclusion in Faculty Publications: Department of Entomology by an authorized administrator of DigitalCommons@University of Nebraska - Lincoln. 


\title{
Distribution and Inhibition of Esterases in Various Body Tissues of Susceptible and Resistant German Cockroaches (Dictyoptera: Blattellidae)
}

\author{
NO-JOONG PARK AND SHRIPAT T. KAMBLE ${ }^{1}$ \\ Department of Entomology, University of Nebraska-Lincoln, Lincoln, NE 68583-0816
}

\begin{abstract}
Ann. Entomol. Soc. Am. 92(4): 556-562 (1999)
ABSTRACT The distribution and inhibition of esterase activity among body of the resistant Crawford and susceptible CSMA strains of male German cockroach, Blattella germanica (L.), were evaluated with $\alpha$ - and $\beta$-naphthyl esters using a spectrophotometric assay and native polyacrylamide gel electrophoresis. The esterase activities in the Crawford strain were significantly higher than in the CSMA strain in most tissues except midgut and male genitalia, where the activities were similar. In both strains, isozyme $a$ was dominant in the brain and fat body and isozymes $c$ and $d$ were more abundant in the midgut; but in addition to isozyme $a$, isozyme $b$ was observed only in the Crawford strain. The $\alpha$-naphthyl butyrate $(\alpha$-NB) and $\beta$-naphthyl acetate $(\beta$-NA) esterase activities in the brain of both strains were completely inhibited by most inhibitors (DEF, 3,4-dichloroisocoumarine, paraoxon, pepstatin $\mathrm{A}$, and propoxur). However, in the midgut tissue and contents, the activities and inhibition patterns of the $\alpha$-NB and $\beta$-NA esterase were apparently different from the brain and between strains. The complete inhibition by paraoxon was observed regardless of the strain, substrate type, and body part for enzyme source. In esterase inhibition on native PAGE gels, paraoxon completely inhibited the activity of most esterases similar to the results from spectrophotometric assay. In addition, the esterase $b$ was observed from the whole body homogenates of several German cockroach resistant strains on native PAGE analysis.
\end{abstract}

KEY WORDS Blattella germanica, cockroach, esterase, distribution, inhibition

ESTERASES ARE CLASSIFIED as hydrolases, a large and diverse group of enzymes that catalyze the hydrolysis of a wide range of aliphatic and aromatic esters, choline esters, and organophosphorous compounds (Dauterman 1985). Because most insecticides are esters of substituted phosphoric, carbamic, or cyclopropanecarboxylic acids, they are subject to degradation by esterases (Devonshire 1991). General esterases can be resolved by electrophoresis and detected using simple spectrophotometric assays with model substrates such as the esters of $p$-nitrophenol, $\alpha$ - and $\beta$-naphthol (Soderlund and Bloomquist 1990).

The biological function and role of esterases in insecticide resistance from the German cockroach has not been clearly determined because of their multiple forms and nonspecific substrate affinity like in other insects (Maa and Terriere 1983, Devonshire 1991, Siegfried and Scott 1992). The overproduction of esterase isozymes responsible for the sequestration of insecticidal compounds rather than hydrolysis was suggested in resistant German cockroaches (Prabhakaran and Kamble 1995, Scharf et al. 1997). This phenomenon has been observed in many other insects such as peach-potato aphids (Devonshire and Moores 1982), mosquitoes (Cuany et al. 1993), and brown leafhoppers (Chen and Sun 1994).

\footnotetext{
${ }^{1}$ To whom correspondence should be addressed.
}

Despite numerous studies of esterases in insecticide-resistant strains, it is not clear what the normal physiological role and natural substrate of these esterases are. In this study, we examined the distribution of general esterase activity among body parts and inhibition of esterase activity for understanding the basic characteristics of esterases in susceptible and resistant strains of German cockroach.

\section{Materials and Methods}

Chemicals. Technical grade propoxur (>99\% [AI]) and DEF (S.S.S-tributylphosphorotrithioate, 98.1\% pure) were purchased from ChemService (West Chester, PA) and PBO (piperonyl butoxide, 90\% pure) from Aldrich (Milwaukee, WI). Paraoxon (diethyl $p$-nitrophenyl phosphate, $95 \%$ pure), DCI (3,4-dichlorisocoumarin), $\mathrm{N}$-ethylmaleimide, eserine (physostigmine), and pepstatin A (90\% pure) were purchased from Sigma (St. Louis, MO). All other biochemical and electrophoresis reagents were obtained from Bio-Rad (Hercules, CA) and Sigma.

Insects. Insecticide-susceptible (CSMA) and resistant (Crawford) German cockroaches were basically used in this experiment. Four resistant stains (Baygon-R, Las Palms, Morris, and Puerto Rico) were used only to confirm the esterase $b$ from the whole body homogenate. German cockroach strains collected 
from Las Palms, Morris, and Puerto Rico strains were obtained from M. Ross (Virginia Polytechnic Institute and State University, Blacksburg, VA) in 1996, and they were determined as multiresistant strains (N.J.P., unpublished data). Characteristics of Baygon- $\mathrm{R}$ and Crawford strains used in this study have been published previously (Prabhakaran and Kamble 1995, Park and Kamble 1998).

All strains of German cockroach were reared on Purina dog chow (Ralston Purina, St. Louis, MO) and water, and maintained in Plexiglas containers $(30.3 \mathrm{~cm}$ wide by $30.3 \mathrm{~cm}$ high by $30.3 \mathrm{~cm}$ deep). Cockroach colonies were maintained at $25 \pm 2^{\circ} \mathrm{C}, 60 \pm 10 \% \mathrm{RH}$, and a photoperiod of 12:12 (L:D) h.

Preparation of Enzyme. Each body region or tissue of German cockroach male of CSMA and Crawford strains used in the experiment was collected by the dissection under a stereomicroscope. Thirty brains were collected from heads dissected from male German cockroaches of each strain, and homogenized in $300 \mu \mathrm{l}$ of ice-cold $50 \mathrm{mM}$ Tris-HCl buffer (pH 7.8). The entire alimentary canal and male genitalia were carefully removed from the decapitated body after removal of the last 1 or 2 abdominal segments using 2 fine tweezers. Each remaining tissue (foregut, midgut, hindgut, Malpighian tubules, male genitalia, fat body) was collected from 10 male cockroaches of each strain, and homogenized in $300 \mu$ l of ice-cold $50 \mathrm{mM}$ Tris- $\mathrm{HCl}$ buffer ( $\mathrm{pH}$ 7.8). The homogenization was conducted with a microcentrifuge tube tissue grinder (Kontes' Pellet Pestle, Fisher, Pittsburgh, PA) using a cordless motor (Fisher). The homogenate was centrifuged for $20 \mathrm{~min}$ at $4^{\circ} \mathrm{C}$ at $10,000 \times g$ and the supernatant was used as the enzyme source for esterase activity assays and native polyacrylamide gel electrophoresis. The whole body homogenates from all 6 strains were prepared as per methods of Park and Kamble (1998) and used for the native PAGE analysis of esterase isozyme pattern among German cockroach strains.

For the inhibition study, homogenates were extracted from the brain, midgut, and midgut contents, as described in the previous paragraph with some modification for midgut and midgut contents. The midgut contents were extracted through low speed centrifugation for $10 \mathrm{~min}$ at $4^{\circ} \mathrm{C}$ at $3,000 \times g$ after the disruption of intact midgut in the buffer by vortexing for $10 \mathrm{~s}$. The supernatants were recentrifuged at $10,000 \times g$, and the supernatants were used as a midgut contents sample. The pellets from low speed centrifugation were resuspended in the buffer, and homogenized with a tissue grinder. After centrifugation at $4^{\circ} \mathrm{C}$ at $10,000 \times g$, the supernatants were collected as a sample of the midgut contents.

Protein, Esterase Assay, and Inhibition. The protein concentration was determined by the method of Bradford (1976). Bovine serum albumin was used to obtain the standard curve. Total nonspecific esterase activity was measured according to the technique of Van Asperen (1962), with some modifications for $1 \mathrm{ml}$ assay volume. The enzyme assay was conducted by measuring the production of $\alpha$ - and $\beta$-naphthol from the substrates of $\alpha$-naphthyl acetate ( $\alpha$-NA), propionate
$(\alpha$-NP), butyrate $(\alpha-\mathrm{NB})$, and $\beta$-naphthyl acetate $(\beta$ NA), respectively. Each sample was added to make a final volume of $1 \mathrm{ml}$ of reaction mixture with $50 \mu \mathrm{l}$ of enzyme solution containing $1 \mu \mathrm{g}$ of protein, and $20 \mu \mathrm{l}$ of $6.25 \mathrm{mM}$ substrate in $50 \mathrm{mM}$ Tris-HCl buffer $(\mathrm{pH}$ 7.8). The reaction was initiated by the addition of $20 \mu \mathrm{l}$ of $6.25 \mathrm{mM}$ substrate and incubated at $38^{\circ} \mathrm{C}$. The reaction was stopped after $10 \mathrm{~min}$ and dark blue color for $\alpha$-naphthol or red color for $\beta$-naphthol was developed by addition of $166 \mu$ l of stop solution ( $0.3 \%$ diazo blue $\mathrm{B}$ in $3.5 \%$ sodium lauryl sulfate). The absorbance at 600 $\mathrm{nm}$ for $\alpha$-naphthol or $555 \mathrm{~nm}$ for $\beta$-naphthol was read against an enzyme blank 10 min later, and the concentration of hydrolyzed substrate was determined from the standard curves of $\alpha$-naphthol and $\beta$-naphthol, respectively.

For the inhibition study, $100 \mathrm{mM}$ of each inhibitor (DCI, DEF, eserine, N-ethylmaleimide, and propoxur) was prepared in methanol, and the concentrations for paraoxon and pepstatin A were $10 \mathrm{mM}$ and $0.1 \%$, respectively. Each reaction tube containing enzyme was incubated with $10 \mu \mathrm{l}$ of each inhibitor for 10 min to allow irreversible inhibitors to react or reversible inhibitors to equilibrate at $38^{\circ} \mathrm{C}$ before reaction with substrate.

Native PAGE and Inhibition. Native polyacrylamide gel electrophoresis was performed in a vertical electrophoresis unit (Protean II mini electrophoresis cell, Bio-Rad, Hercules, CA) by using a 10\% separating gel and 2.5\% stacking gel, with a discontinuous trisglycine buffer system. Samples of prepared enzyme were diluted 4-fold with stacking gel buffer so that they contained $10 \%$ glycerol and $0.002 \%$ bromophenol blue as tracking dye, and $10 \mu \mathrm{g}$ of protein for each sample was loaded onto the gel. Electrophoresis was conducted at a constant $100 \mathrm{~V}$ for $\approx 2 \mathrm{~h}$ in a $4^{\circ} \mathrm{C}$ cold chamber.

For the inhibition study, each gel was incubated in the same buffer containing $100 \mu \mathrm{l}$ of each inhibitor solution $(0.2 \mathrm{mM}$ final concentration of DCI, DEF, eserine, and propoxur, and $0.02 \mathrm{mM}$ for paraoxon) for $10 \mathrm{~min}$ at room temperature before starting the reaction with substrate. Gels were stained for esterase activity in $100 \mathrm{ml}$ of $50 \mathrm{mM}$ sodium phosphate buffer (pH 7.0), $0.5 \%$ (by volume) $50 \mathrm{mM}$ of $\alpha$-NB dissolved in acetone, and $0.04 \mathrm{~g}$ of fast blue RR salt to visualize produced $\alpha$-naphthol. The incubation continued at room temperature for $30 \mathrm{~min}$. After staining, gels were transferred to a destaining chamber containing 5\% acetic acid solution. Gels and cellophane membranes were placed in the drying solution containing $0.3 \%$ glycerol and $20 \%$ methanol, and the fixed gels were dried between 2 sheets of filter paper in a gel dryer (model 583 Gel Dryer, Bio-Rad).

\section{Results}

Distribution of Esterases. Esterase activities in the resistant Crawford strain were significantly higher than those activities in the susceptible CSMA strain in most tissues examined, except in male genitalia, where activities were similar (Fig. 1). Esterase activities from 


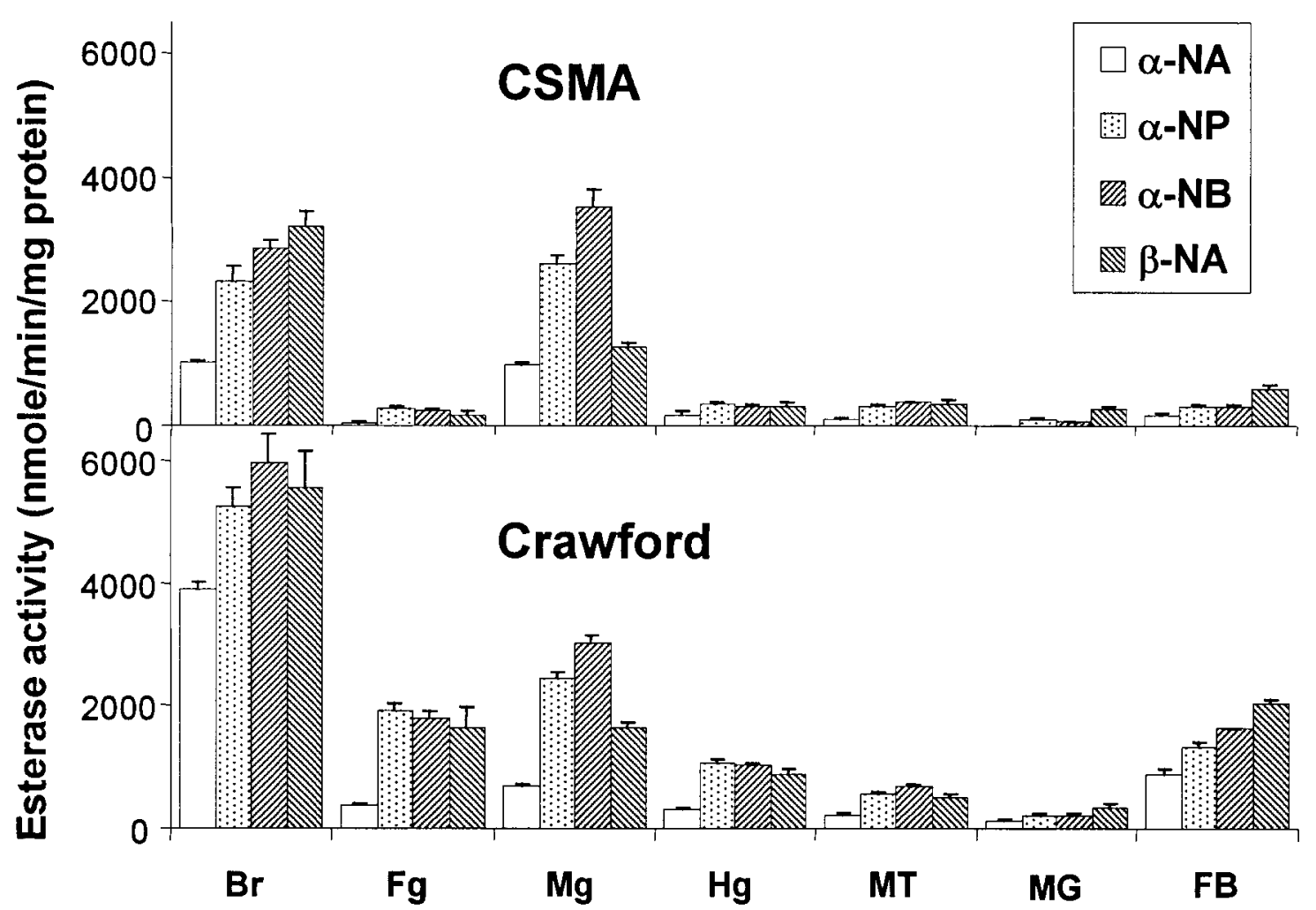

Fig. 1. Activity of nonspecific esterases from the body parts of the susceptible (CSMA) and resistant (Crawford) German cockroaches toward $3 \alpha$-naphtholic esters and a $\beta$-naphthyl acetate. $\mathrm{Br}$, brain; Fg, foregut; $\mathrm{Mg}$, midgut; $\mathrm{Hg}$, hindgut; MT, Malpighian tubules; MG, male genitalia; FB, fat body. Mean \pm SE of 2 preparations with 3 replications.

the brain and midgut homogenates were generally higher than in other homogenates, in both susceptible and resistant strains with all substrate types. In particular, the activities from brain tissue were much greater in the resistant strain than those in the susceptible strain (3.8-fold with $\alpha$-NA, 2.3-fold with $\alpha$-NP, 2.1-fold with $\alpha$-NB, and 1.7-fold with $\beta$-NA, respectively). The $\beta$-NA esterase activity was significantly higher in brain and fat body tissue than those in other tissues, and it also was much greater in the resistant strain than that in the susceptible strain. Moreover, the $\alpha$-NP and $\alpha$-NB esterase activity in the midgut tissue was much higher than $\alpha$-NA and $\beta$-NA esterase activities in both strains.

Esterase isozyme analysis with native polyacrylamide gel electrophoresis revealed 5 major bands with a high capability of hydrolyzing $\alpha$-naphthyl butyrate (Fig. 2). Those major bands were previously designated as $a, b, c, d$, and $e$ according to their mobility (Park and Kamble 1998). In the susceptible CSMA strain, the mobile isozyme $a$ was the dominant esterase existing more intensely in the brain and fat body, and esterases $c$ and $d$ were the major esterases in the midgut. Esterases $c$ and $d$ were 2 dominant isozymes in the midgut content but esterase $d$ was the only dominant isozyme in the midgut tissue of both strains. In contrast, esterases $a$ and $b$ were dominant in the brains of the resistant Crawford strain, whereas esterase $b$ was not observed from the susceptible CSMA strain. The distribution of other esterase isozymes in most tissues was similar to the susceptible CSMA strain.

Inhibition of Esterases. The $\alpha$-NP and $\beta$-NA esterase activities in the brain of both strains were completely inhibited by most inhibitors (DEF, DCI, paraoxon, pepstatin $\mathrm{A}$, and propoxur) and strongly inhibited by $\mathrm{N}$-ethylmaleimide (Fig. 3). In the midgut tissue, the $\alpha$-NB esterase activity was much higher in the Crawford strain than in the CSMA strain, whereas the $\beta$-NA esterase activity was similar in both strains (Fig. 4). However, the activities of $\alpha$-NB and $\beta$-NA esterases in the resistant strain were more sensitive to inhibition by DEF, DCI, and $N$-ethylmaleimide than those in the susceptible strain. The $\alpha$-NB and $\beta$-NA esterase activities in the midgut content showed similar level of activity, and the inhibition by the inhibitors except $\mathrm{N}$-ethylmaleimide was more sensitive in the Crawford strain than in the CSMA strain (Fig. 5). Complete inhibition by paraoxon was observed regardless of the strain, substrate type, and tissue for enzyme source (Figs. 3-5).

The $\alpha$-NB esterase activities of the brain, midgut tissue, and midgut contents were inhibited by 5 selected inhibitors (DCI, DEF, eserine, paraoxon, and 
CSMA

$\mathrm{Br}$
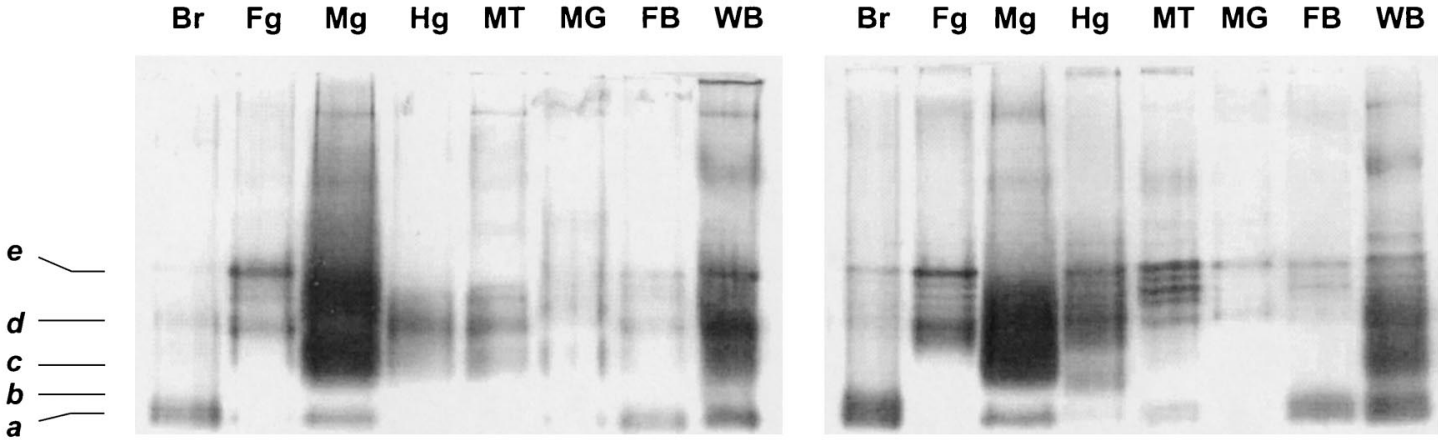

Fig. 2. Nonspecific esterase isozymes from the body parts of the susceptible (CSMA) and resistant (Crawford) German cockroaches, separated by native polyacrylamide gel electrophoresis and visualized with $\alpha$-naphthyl butyrate as substrate. $\mathrm{Br}$, brain; Fg, foregut; Mg, midgut; Hg, hindgut; MT, Malpighian tubules; MG, male genitalia; FB, fat body; WB, whole body. Letters $a-e$ indicate the 5 major isozyme bands of increasing mobility in the native gel.

propoxur) after separation by native PAGE (Fig. 6). In noninhibited controls, the esterase isozymes $a$ and $b$ were observed as dominant esterases in the brain preparation of the susceptible and resistant strains. Esterase isozyme $d$ was the most intensely stained band in the midgut tissue, and at least 3 different forms including isozyme $c$ were abundant in the midgut contents. DCI completely inhibited the activity of esterase isozyme $a, b$, and minor esterase bands in the brain preparations from both strains, and slightly inhibited the activity of midgut tissue and contents. DEF had no effect on the most major isozymes in all 3 samples for both strains, except the inhibition of some minor esterases in the brain preparation. Eserine moderately inhibited most esterases observed in every tissue of both strains, compared with the noninhibited gel. Paraoxon was the most potent inhibitor of every esterase isozyme. However, a slight activity of isozyme $d$ was observed from the sample of midgut tissue and
BRAIN

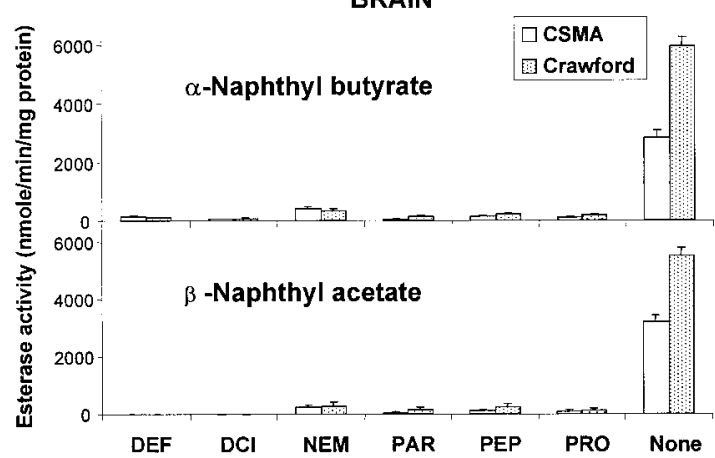

Fig. 3. Inhibition of nonspecific esterase activity in brain homogenate of CSMA and Crawford strains of German cockroach. DEF, S. S. S-tributylphosphorotrithioate; DCI, 3,4dichloroisocoumarin; NEM, N-ethylmaleimide; PAR, paraoxon; PEP, pepstatin A; PRO, propoxur; None, no inhibition. Mean $\pm \mathrm{SE}$ of 2 preparations with 3 replications. contents in both strains. Propoxur strongly inhibited the activity of isozyme $a$ and $b$ in brain samples from both strains, and activities of minor esterases in brain sample and other isozymes in midgut tissue and midgut contents were slightly inhibited. terns among different strains were similar to each other except the existence of esterase $b$ in every resistant strain examined in this experiment. The elevated activity of esterase $b$ was observed from the whole body homogenates of the resistant Baygon-R, Las Palms, Morris, and Puerto Rico strains of German cockroach (Fig. 7).

\section{Discussion}

The involvement of increased carboxylesterase activity in insecticide-resistant insects has been recognized in many insect species (Devonshire and Moores
Esterase $\boldsymbol{b}$ in Resistant Strains. The isozyme pat-



Fig. 4. Inhibition of nonspecific esterase activity in midgut tissue homogenate of CSMA and Crawford strains of German cockroach. Abbreviations for inhibitors in $\mathrm{x}$-axis are the same as those in Fig. 3. Mean \pm SE of 2 preparations with 3 replications. 


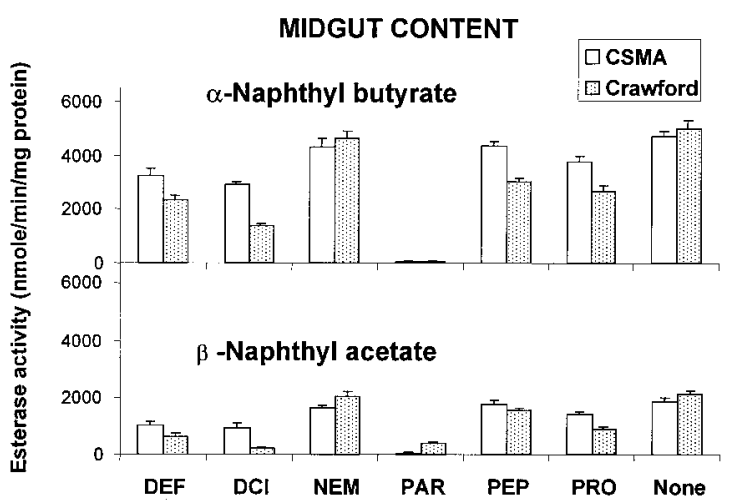

Fig. 5. Inhibition of nonspecific esterase activity in midgut contents homogenate of CSMA and Crawford strains of German cockroach. Abbreviations for inhibitors in $\mathrm{x}$-axis are the same as those in Fig. 3. Mean \pm SE of 2 preparations with 3 replications.

1982, Cuany et al. 1993, Xu and Brindley 1994, Chen and Sun 1994, Chiang and Sun 1996). Increased esterase activity also was observed in many insecticideresistant strains of German cockroach (Siegfried and Scott 1992; Prabhakaran and Kamble 1995 and 1996; Scharf et al. 1997; Park and Kamble 1998). In the German cockroach, it has been suggested that carboxylesterases act to sequester OP compounds as a

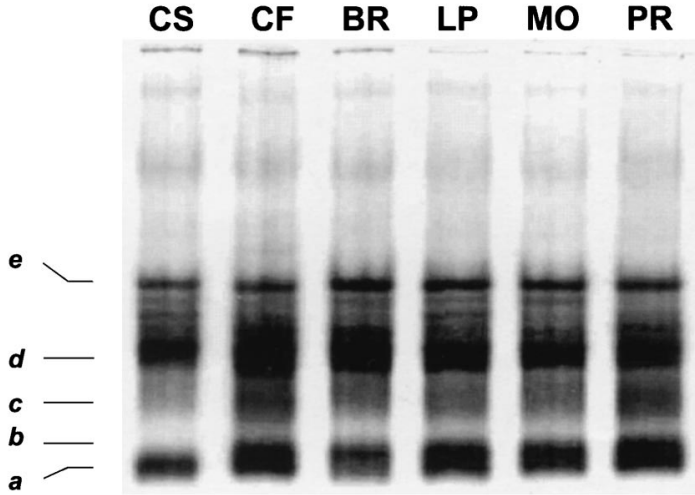

Fig. 7. Nonspecific esterase isozymes from whole body homogenates of a susceptible (CSMA) and 5 resistant German cockroach strains, separated by native polyacrylamide gel electrophoresis and visualized with $\alpha$-naphthyl butyrate as substrate. CS, CSMA; CF, Crawford; BR, Baygon-R; LP, Las Palms; MO, Morris; PR, Puerto Rico.

result of high oxon affinity for carboxylesterase active sites (Prabhakaran and Kamble 1995, Scharf et al. 1997). However, the resistance-conferring mechanism by German cockroach esterases in a given tissue is still unclear, because previous results were obtained from the homogenates of abdomen (Siegfried and

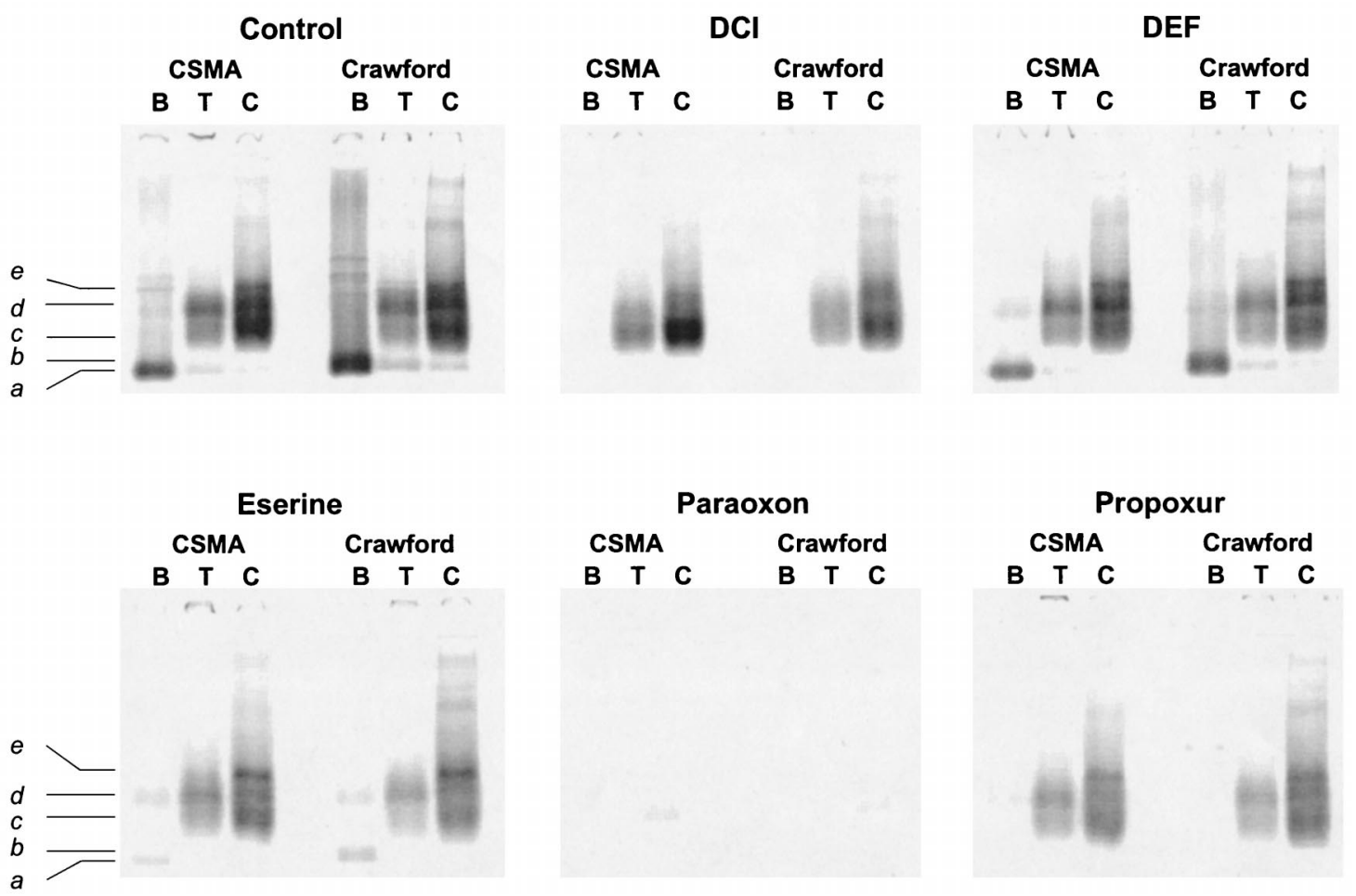

Fig. 6. Inhibition of nonspecific esterase isozymes from the body parts of the susceptible (CSMA) and resistant (Crawford) German cockroaches, separated by native polyacrylamide gel electrophoresis by 5 different inhibitors. B, brain; $\mathrm{T}$, midgut tissue; $\mathrm{C}$, midgut contents. 
Scott 1992), or of decapitated (Prabhakaran and Kamble 1995) or whole bodies (Scharf et al. 1997).

In this study, we found esterases in most German cockroach body tissues with different levels of activity (Fig. 1) and potentially various molecular forms (Fig. 2). Higher esterase activity was found in the midgut and brain than other body tissues from both strains. It is interesting that the increased activity in the resistant Crawford strain was observed from the brain, foregut, hindgut, and fat body homogenate, not from the midgut. It is assumed that the main fraction of the total esterase activity in the German cockroach exists in the midgut because of its digestive function as observed in the whole body homogenate separated on the native gel (Fig. 2). The esterases $a, b$, and $e$ were much more abundant in the resistant Crawford strain than in the susceptible CSMA. Esterase $b$ in the Crawford strain seems to have similar substrate specificity to esterase $a$ in the brain tissue of both strains. Both esterases $a$ and $b$ were observed in most body tissues except foregut and hindgut with various activity in the native PAGE analysis. Further investigation is needed to understand the biological function and involvement of these brain esterase isozymes in detoxification.

DEF, DCI, $\mathrm{N}$-ethylmaleimide, paraoxon, pepstatin $\mathrm{A}$, and propoxur inhibited both the $\alpha$-NP and $\beta$-NA esterase activities in the brains of both strains (Fig. 3 ). This suggests that both isozymes $a$ and $b$ in the brain are vulnerable and possess more broad substrate specificity than other esterases, as shown in the similar levels of $\alpha$-NB and $\beta$-NA esterase activity. However, in native PAGE those activities were not inhibited by DEF, a synergist believed to inhibit esterase activity (Soderlund and Bloomquist 1990). However, DCI, a covalent reacting, irreversible inhibitor of serine protease (Harper et al. 1985), and propoxur, a carbamate insecticide that inhibits some esterases (Devonshire 1991, Scharf et al. 1997), consistently inhibit the esterase activity of the brain in both spectrophotometric assays and native gel. The inhibition of esterase activity by DEF was observed in spectrophotometric assay with the whole body sample of the pyrethroidresistant strain of Egyptian cotton leafworm (Riskallah 1983). Considering the synergistic and moderate toxic character of DEF, it is assumed that the DEF would reversibly react with the esterase $a$ and $b$ of the brain. The inhibition observed only in the spectrophotometric assay could be explained as a result of a much larger molar excess $(1 \mathrm{mM})$ of inhibitors than the amount of enzyme ( $1 \mu \mathrm{g}$ of protein) (Bieth 1995) or poor permeability into the native gel owing to the low solubility in water $\left(2.3 \mathrm{ppm}\right.$ at $20^{\circ} \mathrm{C}$ ) (Anonymous $1995)$. In the reaction with a gel, however, $0.1 \mathrm{mM}$ of each inhibitor was incorporated into $10 \mu \mathrm{g}$ of protein per lane.

In the midgut tissue, esterase $d$ was the dominant isozyme (Fig. 6). The $\alpha$-NB esterase activity in the resistant Crawford strain was much more sensitively inhibited by DEF, DCI, and $N$-ethylmaleimide, whereas $\beta$-NA esterase activity was not inhibited by $\mathrm{N}$-ethylmaleimide (Fig. 4). $\mathrm{N}$-ethylmaleimide is a cysteine peptidase inhibitor rapidly reacting with fully thiol-activated enzymes, and pepstatin A is a tightbinding inhibitor of aspartic proteases (Barrett 1994). The different inhibition pattern between the reactions with each substrate implies that the midgut tissue contains different types of esterases. Further study of midgut esterase should involve substrate specificity, inhibition kinetics, and enzyme activation.

The midgut contents are composed of a mixture of various digestive hydrolases such as peptidases, lipases, and carbohydrate digestive enzymes (Chapman 1971). The $\alpha$-NB and $\beta$-NA esterase activities in the midgut contents were poorly inhibited by most inhibitors except paraoxon (Figs. 5 and 6). Perhaps the esterases in the midgut contents would be a mixture of unidentified hydrolases that might share the catalytic activity toward the naphthyl esters and strongly bind to paraoxon. In the spectrophotometric assay with the homogenate from the mixed body tissues, these esterases will serve as a major esterase activity in whole body homogenate as show in enzymatic visualization of native gels (Fig 7). The substrate specificity and exact biological function of these esterases from gut contents are still unknown. Based on our result, it is probable that these esterases are not responsible for esterase-related detoxification mechanisms, although they obviously consist of the major fraction of the total esterase activity from whole body and are strongly inhibited by paraoxon.

Paraoxon was the most potent inhibitor against every esterase isozyme in both spectrophotometric assay and native gel; however, the activity of esterase $d$ is not fully inhibited by several inhibitors in midgut tissue and contents of both strains (Fig. 6). Propoxur completely inhibited the activity of esterase $a$ and $b$ from various body parts (Fig. 6); and eserine, a strong acetylcholinesterase inhibitor, did not significantly inhibit any of the major esterases in the native gel (Fig. 6). According to the definition by Aldridge (1953), all esterases observed in this study are classified as B esterases because of their strong inhibition by paraoxon, and all of them can be classified as carboxylesterases, as a result of their lack of inhibition by eserine (Devonshire 1991).

The major difference between susceptible and other resistant strains is the existence of esterase $b$ in the resistant strains (Fig. 7). Our data show that the esterases $c$ and $d$ are dominant in the midgut tissue and midgut contents. These 2 esterases observed as major fractions of esterase activity from the whole body homogenate in native PAGE. Further, esterases $c$ and $d$ were less sensitive to all inhibitors except paraoxon than other esterases in other tissues (Fig. 6). Both of the carboxylesterases $a$ and $b$ were dominant in the brain tissue of the resistant Crawford strain, whereas esterase b was not detected from the susceptible CSMA strain. Moreover, we observed esterase $b$ in other body tissues of the Crawford strain, and could detect significant enzymatic activity of this particular esterase in whole body homogenate of several resistant strains by the native gel electrophoresis. Here, we suggest the possibility that the esterases in brain might play an important role in insecticide resistance of 
German cockroach. Further studies of enzyme kinetics toward various substrates and inhibitors, and study of the role of these esterases in the insect body, are clearly required to understand their involvement in resistance.

\section{Acknowledgments}

We are grateful to M. H. Ross (Department of Entomology, Virginia Polytechnic Institute and State University) for providing the valuable resistant strains of German cockroach. We also thank Michael Scharf and Blair Siegfried (Department of Entomology, University of Nebraska) for their critical review of the manuscript. This article is published as paper No. 1006, Journal Series, Nebraska Agricultural Division and contribution No. 12416, Department of Entomology, Institute of Agriculture and Natural Resources, University of Nebraska-Lincoln.

\section{References Cited}

Aldridge, W. N. 1953. Serum esterases. 1. Two types of esterase (A and B) hydrolyzing $p$-nitrophenyl acetate, propionate, and butyrate, and a method for their determination. Biochem. J. 53: 110-117.

Anonymous. 1995. Farm chemicals handbook '95. Meister, Willoughby, $\mathrm{OH}$.

Barrett, A. J. 1994. Classification of peptidases. Methods Enzymol. 244: 1-15.

Bieth, J. G. 1995. Theoretical and practical aspects of proteinase inhibition kinetics. Methods Enzymol. 248: 59 - 84.

Bradford, M. M. 1976. A rapid and sensitive method for the quantitation of microgram quantities of protein utilizing the principle of protein dye binding. Anal. Biochem. 72: $248-254$

Chapman, R. F. 1971. The insects: structure and function, 3rd ed. Hodder and Stoughton, London.

Chen, W. L., and C. N. Sun. 1994. Purification and characterization of carboxyl esterase of rice brown planthopper, Nilaparvata lugens Stal. Insect Biochem. Mol. Biol. 24: 347-355.

Chiang, S. W., and C. N. Sun. 1996. Purification and characterization of carboxylesterases of a rice green leafhopper Nephotettix cincticeps Uhler. Pestic. Biochem. Physiol. 54: 181-189.

Cuany, A., J. Handani, J. Berge, D. Fournier, M. Raymond, G. P. Georghiou, and N. Pasteur. 1993. Action of esterase $\mathrm{B} 1$ on chlorpyrifos in organo phosphate resistant Culex mosquitoes. Pestic. Biochem. Physiol. 45: 1-6.

Dauterman, W. C. 1985. Insect metabolism: extramicrosomal, pp. 713-730. In G. A. Kerkut and L. I. Gilbert [eds.], Comprehensive insect physiology biochemistry and pharmacology, vol. 12. Pergamon, Oxford.

Devonshire, A. L. 1991. Role of esterases in resistance of insects to insecticides. Biochem. Soc. Trans. 19: 755-759.
Devonshire, A. L., and G. D. Moores. 1982. A carboxylesterase with broad substrate specificity causes organophosphorous, carbamate and pyrethroid resistance in peach-potato aphids. Pestic. Biochem. Physiol. 18: 235246.

Harper, J. W., K. Hemmi, and J. C. Powers. 1985. Reaction of serine proteases with substituted isocoumarines: discovery of 3,4-dichloroisocoumarine, a new general mechanism based serine protease inhibitor. Biochemistry 24: 1831-1841.

Maa, W. C., and L. C. Terriere. 1983. Age-dependent variation in enzymatic and electrophoresis properties of house fly (M. Domestica) carboxylesterases. Comp. Biochem. Physiol. 74C: 461-467.

Park, N. J., and S. T. Kamble. 1998. Comparison of esterases between life stages and sexes of resistant and susceptible strains of German cockroach (Dictyoptera: Blattellidae). J. Econ. Entomol. 91: 1051-1057.

Prabhakaran, S. K., and S. T. Kamble. 1995. Purification and characterization of an esterase isozyme from insecticide resistant and susceptible strains of German cockroach, Blattella germanica (L.). Insect Biochem. Mol. Biol. 25: 519-524.

Prabhakaran, S. K., and S. T. Kamble. 1996. Biochemical characterization and purification of esterases from three strains of German cockroach, Blattella germanica. Arch. Insect Biochem. 31: 73-86.

Riskallah, M. R. 1983. Esterases and resistant to synthetic pyrethroids in the Egyptian cotton leafworm. Pestic. Biochem. Physiol. 19: 184-189.

Scharf, M. E., J. Hemingway, G. J. Small, and G. W. Bennett. 1997. Examination of esterase from insecticide resistant and susceptible strains of the German cockroach, Blattella germanica (L.). Insect Biochem. Molec. Biol. 27: 489-497.

Siegfried, B. D., and J. G. Scott. 1992. Biochemical characterization of hydrolytic and oxidative enzymes in insecticide resistant and susceptible strains of the German cockroach (Dictyoptera: Blattellidae). J. Econ. Entomol. 85: 1092-1098.

Soderlund, D. M., and J. R. Bloomquist. 1990. Molecular mechanisms of insecticide resistance, pp. 58-97. In R. T. Roush and B. E. Tabashnik [eds.], Pesticide resistance in arthropods. Chapman \& Hall, New York.

Van Asperen, K. 1962. A study of housefly esterases by means of a sensitive colorimetric method. J. Insect Physiol. 8: 401-416.

$\mathrm{Xu}, \mathrm{G}$., and W. A. Brindley. 1994. Esterase isozymes in Lygus hesperus: characterization and relationship with organophosphate resistance. Pestic. Sci. 42: 273-280.

Received for publication 19 October 1998; accepted 15 March 1999. 